\title{
Food Availability at the Household Level in the European Union'
}

\section{The DAFNE Network (Only for the Countries Participating in the ENHR 2009 and Presented in This Report)}

Austria

Institute of Nutritional Sciences,

University of Vienna

I. Elmadfa, H. Friesling,

A. Suchomel

Belgium

University of Gent, Faculty of

Agricultural and Applied Biological

Sciences, Department of Food

Technology and Nutrition

A.M. Remaut - de Winter, AP.

Cueto Eulert

National Institute of Statistics,

Brussels

Buermans, L. Merckx

Cyprus

Department of Medical and Public

Health Services, Ministry of Health

Agrotou A., Markidou E.

Statistical Service of the

Republic of Cyprus

Onisiforou K.
Finland

Statistics Finland, Helsinki, Finland

MA Berg, A. Pajunen

National Public Health Institute,

Helsinki, Finland

T. Hirvonen

France

Unite Observatoire des Consommations

Alimentaires, AFSSA

JL. Volatier, J. Maffre

Germany

Department of Marketing and

Consumer Research TUM Business

School, Technische Universität

München, Munich, Germany

G. Karg, K Gedrich, K. Wagner

Greece (coordinating center)

Department of Hygiene Epidemiology

and Medical Statistics,

School of Medicine, University of Athens

A. Trichopoulou, A. Naska,

E. Oikonomou, K. Tsiotas, V. Bountziouka.

National Statistical Office, Athens

Douros, I. Tsaousi

${ }^{1}$ Naska $A^{\mathrm{a}}$, Oikonomou $\mathrm{E}^{\mathrm{a}}$, Tsiotas $\mathrm{K}^{\mathrm{a}}$, Bountziouka $\mathrm{V}^{\mathrm{a}, \mathrm{b}}$, Trichopoulou $\mathrm{A}^{\mathrm{a}, \mathrm{b}}$ on behalf of the DAFNE network

${ }^{a}$ Dept. of Hygiene, Epidemiology and Medical Statistics, School of Medicine, National and Kapodistrian University of Athens, ${ }^{b}$ Hellenic Health Foundation, Athens, Greece 
Hungary

National Institute of Food Hygiene and

Nutrition, Budapest

Zajkas, M. Korom

Hungarian Central Statistical Office,

Section of Living Standard Statistics

Surveys

E. Menesi

Ireland

National Nutrition Surveillance Centre, University College, Galway, Ireland

C. Kelleher, S. Friel

Central Statistics Office, Cork

K. McCormack

Italy

National Research Institute for

Food and Nutrition

A. Turrini, S. Martines

Italian Statistical Office (ISTAT)

S. Barcherini

Latvia

Food and Veterinary Service

Food Center

D. Šantare, N. Petruhina

Central Statistical Bureau of Latvia

L. Sparite

Luxembourg

Interdisciplinary Nutrition Policy Group

A. Schmitt

Central Statistics Office

J. Langers, M. Zanardelli

Norway

Institute of Nutrition Research,

University of Oslo

K. Trygg, K. Lund-Iversen

Statistics Norway, Oslo

E. Mork
Poland

National Food and Nutrition Institute

W. Sekula, M Ołtarzewski

Portugal

University of Porto

MD Vaz de Almeida, S. Rodrigues

\section{Slovenia}

Institute of Public Health of the

Republic of Slovenia

M. Gabrijelčič Blenkuš, M. Gregorič,

M. Adamič

Statistical Office of the Republic of

Slovenia

M. Remec

Spain

Departamento de Nutricion y

Bromatologia, Facultat de Farmacia,

Universidad Complutense de Madrid

O. Moreiras, C. Cuadrado

Instituto Nacional de Estadistica,

Madrid

M.L. Boned, P. Seoane Spiegelberg

Sweden

Unit for Preventive Nutrition,

Department of Biosciences and

Nutrition, Karolinska Institute

M. Sjöstrom, E. Poortvliet

\section{United Kingdom}

King's College London, Department of

Nutrition and Dietetics, London

Nelson, S. Burr

Ministry of Agriculture, Fisheries and

Food, National Food Survey Branch,

London

D. Rimmer 


\section{Introduction}

Data for nutrition surveillance can be derived from: Food Balance Sheets (FBS), Household Budget Surveys (HBS) and specifically designed Individual Nutrition Surveys (INS). The Food and Agriculture Organization assembled FBS have traditionally been used by countries with no routine information on food consumption or those interested in undertaking worldwide comparisons of overtime trends in the supply of food commodities at the population level [FAO, 2007a]. Household budget surveys are systematically conducted by National Statistical Offices in country representative samples and aim at collecting, among others, data on food availability at household level. Like FBS, the HBS allow inter-country comparisons on a regular basis but, moving from total population to household level, they further allow the description of the current and developing structure of dietary patterns at national or regional level and of population sub-groups defined on the basis of their sociodemographic characteristics [Trichopoulou, 1992]. Individual-based surveys, when participants' intakes are recorded as adequately as possible, constitute the optimal method for assessing dietary patterns and quantifying determinants and consequences of food choices. Being expensive and labor intensive, however, representative individual-based surveys are regularly undertaken in some countries. Furthermore, differences in study design and data analysis reduce the comparability of results at an international level.

The use of the national HBSs for nutrition monitoring purposes has been evaluated through the EU-supported Data Food Networking (DAFNE) initiative, which built up a regularly updated food-based databank allowing the: (a) identification of dietary patterns prevailing in Europe and of their sociodemographic determinants; [Trichopoulou et al., 2002; Naska et al., 2006], (b) follow up of time trends in food habits; [Trichopoulou and Naska, 2003], and (c) evaluation of nutrition action plans and strategies implemented at national or international level [Trichopoulou, 2001]. The DAFNE network is coordinated by the Department of Hygiene and Epidemiology of the University of Athens Medical School and currently interrelates 26 European countries (Albania, Armenia, Austria, Belgium, Croatia, Cyprus, Finland, France, Germany, Greece, Hungary, Ireland, Italy, Latvia, Luxembourg, Malta, Montenegro, Norway, Poland, Portugal, Serbia, Spain, Slovak Republic, Slovenia, Sweden and the $\mathrm{UK})$.

\section{The DAFNE Methodology}

\section{Data Collection}

Through the standardized and nationally representative HBSs, members of the participating households are asked to record in open questionnaires all foods and beverages available during a reference period, including purchases, contributions from 
own production and food items offered to members as gifts. Data on food quantities consumed in restaurants, canteens and similar establishments are, however, not consistently available. Data collection is accomplished within one year, with due attention to capture seasonal variation in food intake. Trained interviewers visit the households regularly to assure complete data recording and to collect further information on socio- demographic and lifestyle characteristics of the household members through standardised interviewer-administered questionnaires [European Communities, 2003].

\section{Integration of the National HBS Data in the DAFNE Databank}

The collected national datasets are centrally analyzed according to the methodology developed and validated in the DAFNE project (fig. 5.1) [Trichopoulou and Naska, 2001]. Briefly, data are read, cleaned and managed to a format suitable for a common between countries analysis. To improve comparability, food and socio demographic data are post-harmonized. In particular, the national HBS food data are classified under 56 detailed common subgroups, which can be further aggregated to 15 main food groupings [Health and Consumer Protection Directorate General, 2005]. With respect to sociodemographic characteristics, focus is, up to now, put on the locality of the dwelling (classified as rural, semi-urban and urban), the educational level of the household head (elementary, secondary and higher), the occupation of the household head (manual, non-manual, unemployed and retired), and on the household's composition, defined on the basis of the number and the age of the members.

Food quantities available for consumption to each household member are calculated by dividing the household availability by the product of the referent time period and the mean household size, under the assumption of equal distribution of food during the survey period and without making allowances for inedible parts, preparation losses, spoilage on the plate or food offered to domestic pets. Weighting factors are incorporated, whenever necessary, to accommodate national sampling schemes.

\section{Conversion of Expenses to Food Quantities}

Since the primary aim of the HBSs is the derivation of national price indices, attention is given to ensure the complete recording of expenses, while data on food quantities (in terms of $\mathrm{kg}$ or liters) could be missing or incomplete.

The method for converting food expenditure to quantity was applied in three cases (Cyprus, Ireland and Sweden) and included the application of retail prices per unit weight, sought from various sources including national and governmental statistics, food organizations, retailers and consumer surveys. Since collection of the prices was made using various sources from differing years, adjustment was made to equivalent prices for the year of HBS data using national Consumer Price Indices. Simple models were devised and validated into which the expenditure data and retail prices were fitted and resulted in the estimated quantity of food item available in each household [Friel et al., 2001]. 


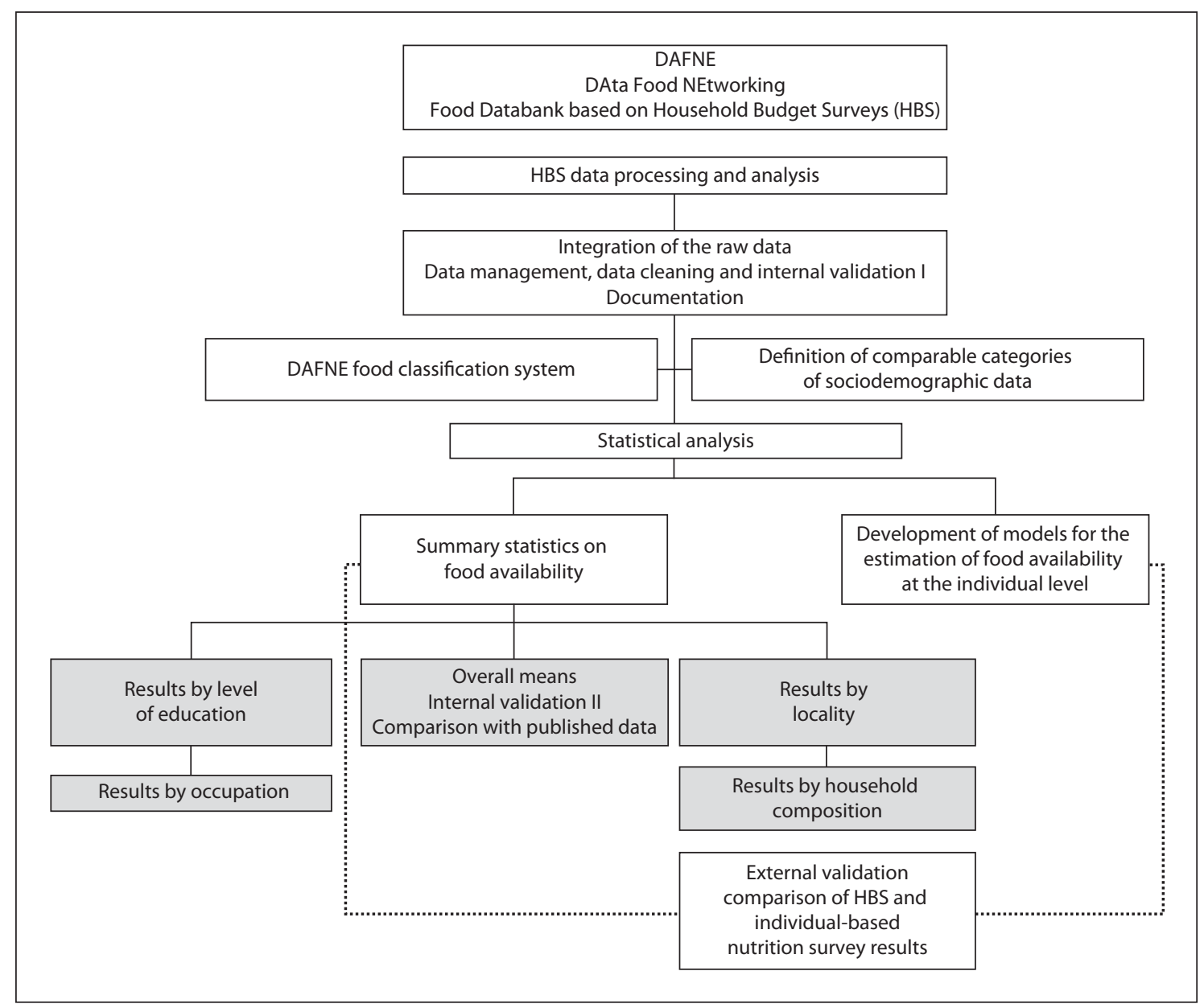

Fig. 5.1. The Household Budget Survey data processing and analysis in the context of the DAFNE initiative.

\section{The DafneSoft Application Tool}

Results on the mean daily per person food availability, based on the DAFNE data, are freely accessible through DafneSoft (http://www.nut.uoa.gr/dafnesoftweb/), an application tool allowing the presentation and exporting of DAFNE data in various formats (tables, bars, pie charts, map presentations) at various levels of detail.

\section{Results Retrieved from the DAFNE Databank - Food Availability in Europe}

Tables 5.1-5.4 present the mean daily individual availability of DAFNE food groups, by European region and country. In tables 5.5-5.7, data on the daily food availability according to the educational level of the household head are also presented. 
Table 5.1. Mean availability of food and beverages in South European countries (unit/person/day)

\begin{tabular}{|c|c|c|c|c|c|}
\hline \multirow[t]{2}{*}{ Survey year } & Cyprus & Greece & Italy & Spain & Portugal \\
\hline & 2003 & 2004-2005 & 1996 & 1998-1999 & 2000 \\
\hline Eggs (pieces) & 0.17 & 0.22 & 0.34 & 0.32 & 0.18 \\
\hline Potatoes, $\mathrm{g}$ & 94 & 124 & 76 & 86 & 180 \\
\hline Pulses, $\mathrm{g}$ & 23 & 14 & 4.1 & 10 & 9.2 \\
\hline Nuts, g & 4.6 & 4.4 & 0.9 & 0.9 & 3.0 \\
\hline Cereals, g & 302 & 246 & 334 & 170 & 239 \\
\hline Milk and milk products, $\mathrm{g}$ & 337 & 296 & 271 & 341 & 275 \\
\hline Cheese, $g$ & 44 & 55 & 49 & 15 & 19 \\
\hline Meat and meat products, $\mathrm{g}$ & 178 & 159 & 136 & 139 & 160 \\
\hline Red meat, $g$ & 98 & 101 & 71 & 55 & 90 \\
\hline Poultry, g & 62 & 42 & 38 & 38 & 44 \\
\hline Processed meat, g & 17 & 13 & 24 & 35 & 17 \\
\hline Vegetables, g & 284 & 283 & 184 & 121 & 137 \\
\hline Fresh vegetables, g & 280 & 256 & 128 & 103 & 126 \\
\hline Processed vegetables, g & 4.0 & 26 & 56 & 18 & 11 \\
\hline Fish and seafood, $\mathrm{g}$ & 18 & 46 & 38 & 61 & 83 \\
\hline Fruits, $\mathrm{g}$ & 252 & 264 & 233 & 195 & 198 \\
\hline Fresh fruit, $g$ & 248 & 263 & 232 & 190 & 196 \\
\hline Processed fruit, $\mathrm{g}$ & 3.5 & 0.82 & 1.4 & 4.8 & 2.3 \\
\hline Fruit and vegetable juices, $\mathrm{ml}$ & 53 & 37 & 9.6 & 30 & 11 \\
\hline Lipids, added, g & 47 & 77 & 63 & 45 & 51 \\
\hline Animal fat, $g$ & 4.0 & 0.88 & 5.6 & 1.0 & 2.7 \\
\hline Vegetable fat, $\mathrm{g}$ & 6.2 & 6.1 & 1.5 & 1.6 & 5.1 \\
\hline Vegetable oils, g & 37 & 69 & 56 & 42 & 42 \\
\hline Beverages, alcoholic, ml & 32 & 60 & 149 & 74 & 125 \\
\hline Beverages, non-alcoholic, ml & 384 & 244 & 824 & 377 & 171 \\
\hline Soft drinks, $\mathrm{ml}$ & 101 & 66 & 42 & 85 & 63 \\
\hline Sugar and sugar products, g & 67 & 34 & 49 & 26 & 30 \\
\hline
\end{tabular}

Source: The DAFNE databank (www.nut.uoa.gr).

Figures 5.2 and 5.3 present the mean daily availability of selected food groups by European region. Values refer to arithmetic means in each region and were calculated by summing the observations (i.e. mean daily availability in each country) and dividing by the number of observations (i.e. number of countries in each region).

The constellation of countries under study possess several interesting characteristics. Cyprus and Greece for example, are Mediterranean countries, which have for centuries been in the cross-road of several historical cultures. Hungary, Latvia and Slovenia were undergoing, to varying extent, through a transition phase during the 
Table 5.2. Mean availability of food and beverages in Central and Eastern European countries (unit/person/day)

\begin{tabular}{|c|c|c|c|c|c|}
\hline \multirow[t]{2}{*}{ Survey year } & Austria & Germany & Hungary & Poland & Slovenia \\
\hline & 1999-2000 & 1998 & 2005 & 1988 & 2002 \\
\hline Eggs (pieces) & 0.50 & 0.36 & 0.48 & 0.61 & 0.38 \\
\hline Potatoes, g & 100 & 115 & 103 & 301 & 110 \\
\hline Pulses, $g$ & n.a. & 0.6 & 3.1 & 3.2 & 5.8 \\
\hline Nuts, $g$ & n.a. & 7.5 & 2.9 & n.a. & 5.5 \\
\hline Cereals, $g$ & 302 & 218 & 253 & 345 & 315 \\
\hline Milk and milk products, $g$ & 284 & 311 & 220 & 381 & 355 \\
\hline Cheese, $g$ & 28 & 55 & 15 & 39 & 36 \\
\hline Meat and meat products, $g$ & 182 & 132 & 160 & 170 & 173 \\
\hline Red meat, g & 65 & 48 & 51 & 62 & 81 \\
\hline Poultry, g & 23 & 16 & 52 & 33 & 31 \\
\hline Processed meat, g & 92 & 59 & 47 & 70 & 54 \\
\hline Vegetables, g & 142 & 180 & 155 & 202 & 173 \\
\hline Fresh vegetables, g & 114 & 142 & 137 & 177 & 148 \\
\hline Processed vegetables, g & 28 & 38 & 18 & 25 & 25 \\
\hline Fish and seafood, $\mathrm{g}$ & 9.3 & 16 & 4.9 & 15 & 13 \\
\hline Fruits, $g$ & 192 & 182 & 119 & 100 & 219 \\
\hline Fresh fruit, $g$ & 186 & 169 & 118 & 96 & 217 \\
\hline Processed fruit, $\mathrm{g}$ & 6.2 & 13 & 1.0 & 4.6 & 2.6 \\
\hline Fruit and vegetable juices, ml & 90 & 123 & 40 & n.a. & 108 \\
\hline Lipids, added, g & 42 & 37 & 50 & 59 & 54 \\
\hline Animal fat, $g$ & 12 & 15 & 13 & 41 & 7.03 \\
\hline Vegetable fat, $\mathrm{g}$ & 11 & 15 & 9.7 & 12 & 6.7 \\
\hline Vegetable oils, g & 20 & 6.4 & 27 & 5.4 & 41 \\
\hline Beverages, alcoholic, ml & 171 & 200 & 58 & n.a. & 141 \\
\hline Beverages, non-alcoholic, ml & 652 & 915 & 577 & 300 & 549 \\
\hline Soft drinks, ml & 116 & 108 & 87 & 34 & 90 \\
\hline Sugar and sugar products, g & 74 & 59 & 51 & 106 & 74 \\
\hline
\end{tabular}

n.a. $=$ Not available

Source: The DAFNE databank (www.nut.uoa.gr).

data collection period. Finland, Norway and Sweden are countries with robust economies and long-lasting national nutrition policies. Furthermore, one should not ignore the diet-related health mandates to which European populations are globally exposed, as well as the increasing prevalence of eating out, which is not considered in these data and has been reported to varyingly concern European populations [Orfanos et al., 2007].

With respect to plant foods, daily availability is higher in the South. Adequate quantities of fruits and vegetables were reported of being available in the Southern 


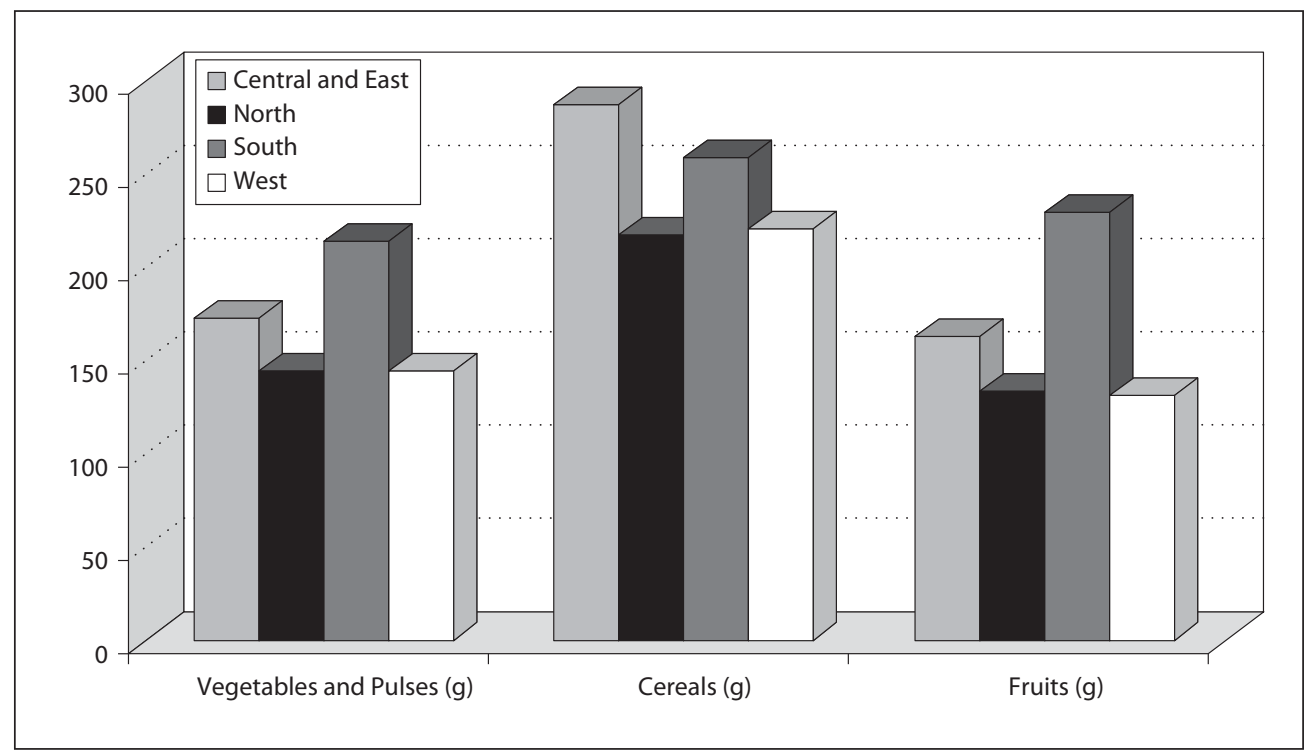

Fig. 5.2. Mean availability (g/person/day) of foods of plant origin by European region. The DAFNE databank.

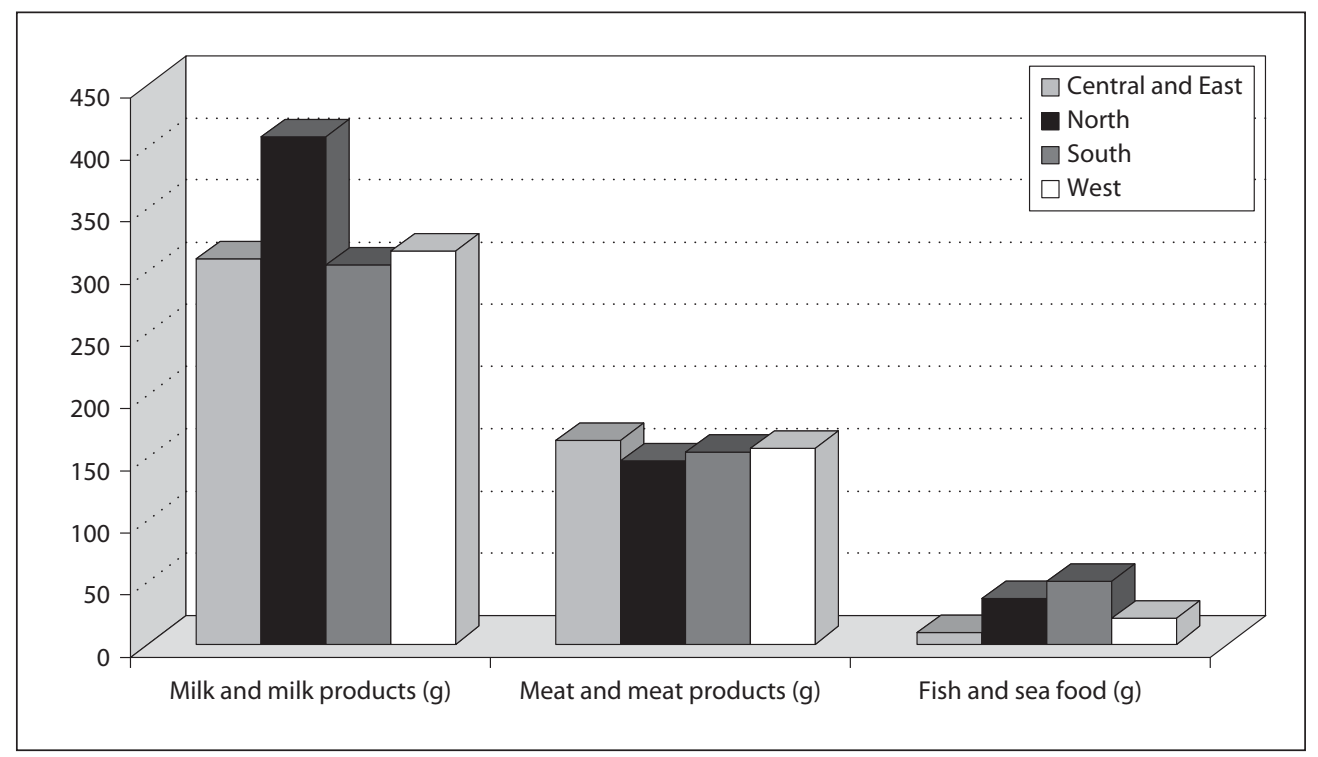

Fig. 5.3. Mean availability ( $g /$ person/day) of foods of animal origin by European region. The DAFNE databank. 
Table 5.3. Mean availability of food and beverages in West European countries (unit/person/day)

\begin{tabular}{llllll}
\hline Survey year & Belgium & France & Ireland & Luxembourg & United Kingdom \\
\cline { 2 - 6 } & 1999 & 1991 & 1999 & 1993 & 1999 \\
\hline Eggs (pieces) & 0.21 & 0.38 & 0.23 & 0.33 & 0.24 \\
Potatoes, g & 97 & 95 & 186 & 163 & 128 \\
Pulses, g & n.a. & 4.9 & 1.1 & 2.3 & 0.99 \\
Nuts, g & 2.6 & 1.7 & 1.2 & 3.1 & 1.7 \\
Cereals, g & 243 & 160 & 290 & 205 & 202 \\
Milk and milk products, g & 256 & 290 & 481 & 235 & 320 \\
Cheese, g & 55 & 48 & 15 & 55 & 20 \\
Meat and meat products, g & 144 & 163 & 166 & 185 & 130 \\
Red meat, g & 54 & 77 & 44 & 83 & 34 \\
Poultry, g & 25 & 36 & 58 & 30 & 33 \\
Processed meat, g & 35 & 33 & 48 & 51 & 25 \\
Vegetables, g & 168 & 183 & 144 & 164 & 150 \\
Fresh vegetables, g & 127 & 157 & 110 & 129 & 103 \\
Processed vegetables, g & 40 & 26 & 34 & 35 & 48 \\
Fish and seafood, g & 24 & 21 & 14 & 28 & 20 \\
Fruits, g & 123 & 157 & 101 & 170 & 106 \\
Fresh fruit, g & 117 & 153 & 94 & 165 & 99 \\
Processed fruit, g & 6.0 & 4.4 & 7.6 & 5.2 & 7.6 \\
Fruit and vegetable juices, ml & 54 & 33 & 57 & 80 & 41 \\
Lipids, added, g & 29 & 41 & 22 & 57 & 26 \\
Animal fat, g & 7.6 & 16 & 8.9 & 22 & 9.7 \\
Vegetable fat, g & 13 & 5.9 & 3.9 & 18 & 11 \\
Vegetable oils, g & 8.4 & 19 & 8.7 & 16 & 202 \\
Beverages, alcoholic, $\mathrm{ml}$ & 135 & 114 & 40 & 175 & 27 \\
Beverages, non-alcoholic, $\mathrm{ml}$ & 500 & 373 & 563 & 1,062 & 181 \\
Soft drinks, ml & 191 & 47 & 122 & 181 & \\
Sugar and sugar products, g & 55 & 44 & 61 & 46 & \\
& & & & & \\
\hline
\end{tabular}

n.a. $=$ Not available

Source: The DAFNE databank (www.nut.uoa.gr).

households and are generally purchased fresh. In Italy, Spain and Portugal and in several other European countries the daily fruit availability is higher than that of vegetables, pointing possibly to a preference for their consumption. In Central and Eastern Europe, part of the deficit appears to be compensated by increased consumption of fruit and vegetable juices. Higher daily availability of cereals and products was reported in Italy, Cyprus and Latvia; although the type of cereals consumed is different. In Italy, pasta and bakery products (incl. pizza) account for $50 \%$, whereas in 
Table 5.4. Mean availability of food and beverages in North European countries (unit/person/day)

\begin{tabular}{|c|c|c|c|c|}
\hline \multirow[t]{2}{*}{ Survey year } & Finland & Latvia & Norway & Sweden \\
\hline & 1998 & 2004 & $\begin{array}{l}1996 / 1997 / \\
1998\end{array}$ & 1996 \\
\hline Eggs (pieces) & 0.31 & 0.55 & 0.34 & 0.40 \\
\hline Potatoes, $\mathrm{g}$ & 111 & 274 & 114 & 85 \\
\hline Pulses, $\mathrm{g}$ & 0.80 & 4.4 & 0.82 & 2.0 \\
\hline Nuts, $g$ & 1.6 & 2.1 & 3.8 & 1.9 \\
\hline Cereals, $\mathrm{g}$ & 205 & 262 & 201 & 200 \\
\hline Milk and milk products, $\mathrm{g}$ & 507 & 292 & 387 & 445 \\
\hline Cheese, $\mathrm{g}$ & 48 & 35 & 39 & 25 \\
\hline Meat and meat products, $\mathrm{g}$ & 149 & 185 & 126 & 128 \\
\hline Red meat, $\mathrm{g}$ & 52 & 67 & 53 & 50 \\
\hline Poultry, g & 12 & 25 & 14 & 18 \\
\hline Processed meat, g & 67 & 85 & 41 & 42 \\
\hline Vegetables, g & 122 & 216 & 109 & 128 \\
\hline Fresh vegetables, $\mathrm{g}$ & 102 & 168 & 84 & 107 \\
\hline Processed vegetables, g & 20 & 48 & 24 & 21 \\
\hline Fish and seafood, $\mathrm{g}$ & 30 & 38 & 50 & 30 \\
\hline Fruits, $g$ & 157 & 120 & 135 & 122 \\
\hline Fresh fruit, $\mathrm{g}$ & 147 & 118 & 129 & 114 \\
\hline Processed fruit, $\mathrm{g}$ & 11 & 2.1 & 6.1 & 8.3 \\
\hline Fruit and vegetable juices, $\mathrm{ml}$ & 82 & 25 & 48 & n.a. \\
\hline Lipids, added, g & 31 & 43 & 32 & 39 \\
\hline Animal fat, $g$ & 11 & 8.6 & 3.6 & 4.2 \\
\hline Vegetable fat, $\mathrm{g}$ & 16 & 9.9 & 26 & 31 \\
\hline Vegetable oils, g & 3.5 & 24 & 1.7 & 3.6 \\
\hline Beverages, alcoholic, ml & 102 & 51 & 73 & n.a. \\
\hline Beverages, non-alcoholic, ml & 531 & 394 & 720 & 492 \\
\hline Soft drinks, ml & 81 & 28 & 177 & 115 \\
\hline Sugar and sugar products, $\mathrm{g}$ & 54 & 72 & 79 & 56 \\
\hline
\end{tabular}

n.a. $=$ Not available

Source: The DAFNE databank (www.nut.uoa.gr).

Cyprus and Latvia bread and rolls correspond to $60 \%$ of the daily cereal availability. Potatoes are mostly a characteristic of Northern/Western diet, as pulses are a characteristic of South food choices.

Regarding added fats and oils, studies have traditionally documented vegetable oils as the lipid of preference in the South and vegetable fat in Central/Northern Europe. The DAFNE results support these findings. Nonetheless, recent data collected in 
Table 5.5. Mean availability of foods and beverages ( $\mathrm{g} \cdot \mathrm{ml} / \mathrm{person} /$ day) by country (survey year) and educational attainment in Central and Eastern European countries

\begin{tabular}{|c|c|c|c|c|c|c|c|c|c|c|c|c|}
\hline & \multicolumn{3}{|c|}{ Austria (1999-2000) } & \multicolumn{3}{|c|}{ Germany (1998) } & \multicolumn{3}{|c|}{ Hungary (2005) } & \multicolumn{3}{|c|}{ Slovenia (2002) } \\
\hline & II/EI & $\mathrm{Sec}$ & $\mathrm{C} / \mathrm{U}$ & II/EI & $\mathrm{Sec}$ & $\mathrm{C} / \mathrm{U}$ & II/EI & $\mathrm{Sec}$ & $\mathrm{C} / \mathrm{U}$ & II/EI & $\mathrm{Sec}$ & $\mathrm{C} / \mathrm{U}$ \\
\hline Cereals and cereal products, $\mathrm{g}$ & 339 & 302 & 305 & n.a. & 216 & 224 & 318 & 244 & 195 & 441 & 289 & 266 \\
\hline Meat and meat products, $\mathrm{g}$ & 197 & 185 & 140 & & 137 & 114 & 183 & 157 & 141 & 247 & 159 & 140 \\
\hline Red meat, $\mathrm{g}$ & 80 & 67 & 38 & & 51 & 40 & 59 & 51 & 38 & 136 & 70 & 60 \\
\hline Poultry, $\mathrm{g}$ & 28 & 23 & 18 & & 16 & 15 & 66 & 48 & 46 & 37 & 31 & 27 \\
\hline Processed meat, $\mathrm{g}$ & 87 & 93 & 83 & & 61 & 52 & 48 & 47 & 47 & 66 & 52 & 49 \\
\hline Fish and seafood, $\mathrm{g}$ & 7.1 & 9.0 & 12 & & 16 & 18 & 3.6 & 5.0 & 6.6 & 10 & 12 & 16 \\
\hline Milk and milk products, $\mathrm{g}$ & 343 & 285 & 267 & & 307 & 322 & 219 & 213 & 246 & 447 & 322 & 358 \\
\hline Cheese, $\mathrm{g}$ & 26 & 28 & 30 & & 53 & 62 & 9.3 & 14 & 25 & 38 & 32 & 46 \\
\hline Vegetables, $\mathrm{g}$ & 193 & 140 & 159 & & 176 & 192 & 178 & 148 & 150 & 229 & 161 & 154 \\
\hline Fresh vegetables, g & 162 & 112 & 123 & & 138 & 151 & 161 & 130 & 128 & 205 & 135 & 130 \\
\hline Proc. vegetables, g & 31 & 27 & 36 & & 37 & 41 & 17 & 18 & 21 & 23 & 26 & 24 \\
\hline Fruit, $\mathrm{g}$ & 260 & 191 & 191 & & 177 & 197 & 114 & 116 & 139 & 241 & 208 & 230 \\
\hline Fresh fruit, $\mathrm{g}$ & 255 & 185 & 182 & & 165 & 183 & 113 & 115 & 137 & 239 & 205 & 226 \\
\hline Processed fruit, $\mathrm{g}$ & 4.9 & 5.9 & 9.9 & & 13 & 14 & 0.57 & 0.93 & 1.6 & 2.3 & 2.4 & 3.4 \\
\hline Fruit and vegetable juices, ml & 94 & 87 & 117 & & 120 & 134 & 22 & 38 & 71 & 94 & 99 & 146 \\
\hline Potatoes, $\mathrm{g}$ & 151 & 103 & 67 & & 117 & 103 & 127 & 100 & 83 & 156 & 102 & 84 \\
\hline Pulses, g & n.a. & n.a. & n.a. & & 0.59 & 0.79 & 4.3 & 2.9 & 2.1 & 8.6 & 5.6 & 3.9 \\
\hline Lipids added, g & 67 & 43 & 30 & & 37 & 34 & 59 & 48 & 41 & 88 & 48 & 39 \\
\hline Animal lipids, g & 14 & 12 & 11 & & 15 & 15 & 20 & 12 & 7.1 & 12 & 6.0 & 4.6 \\
\hline Vegetable fats, $\mathrm{g}$ & 12 & 11 & 6.2 & & 16 & 13 & 10 & 9.4 & 9.8 & 8.9 & 6.1 & 6.1 \\
\hline Vegetable oils, $\mathrm{g}$ & 40 & 20 & 13 & & 6.5 & 5.9 & 29 & 27 & 24 & 67 & 36 & 28 \\
\hline Beverages, alcoholic, ml & 172 & 174 & 142 & & 199 & 212 & 56 & 56 & 70 & 175 & 139 & 114 \\
\hline Beverages, non-alcoholic, ml & 684 & 660 & 551 & & 925 & 887 & 565 & 562 & 648 & 644 & 517 & 545 \\
\hline Soft drinks, ml & 121 & 119 & 86 & & 117 & 81 & 104 & 87 & 65 & 83 & 93 & 88 \\
\hline Sugar and sugar products, $\mathrm{g}$ & 97 & 75 & 57 & & 59 & 56 & 61 & 50 & 41 & 105 & 69 & 57 \\
\hline $\begin{array}{l}\text { n.a. = Not available. } \\
\text { II/EL = Illiterate/Elementary e } \\
\text { Source: } \text { The DAFNE databank }\end{array}$ & N.n & & 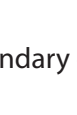 & & & & & & & & & \\
\hline
\end{tabular}

newly emerging markets, such as Slovenia, Latvia and Hungary, indicate higher household availability of oils than fats (animal and vegetable).

In relation to foods of animal origin, the highest daily availability of milk and products, but not cheese, was recorded in Finland, Sweden, Norway and Ireland. Fish and seafood are items whose consumption is shaped through various factors, among which availability/proximity to the sea and cost are dominant. According to the DAFNE data, higher daily fish availability was recorded in Portugal, Spain and Norway. With respect to meat, all countries recorded substantial household acquisitions. The type of 
Table 5.6. Mean availability of foods and beverages ( $\mathrm{g} \cdot \mathrm{ml} /$ person/day) by country (survey year) and educational attainment in South EC

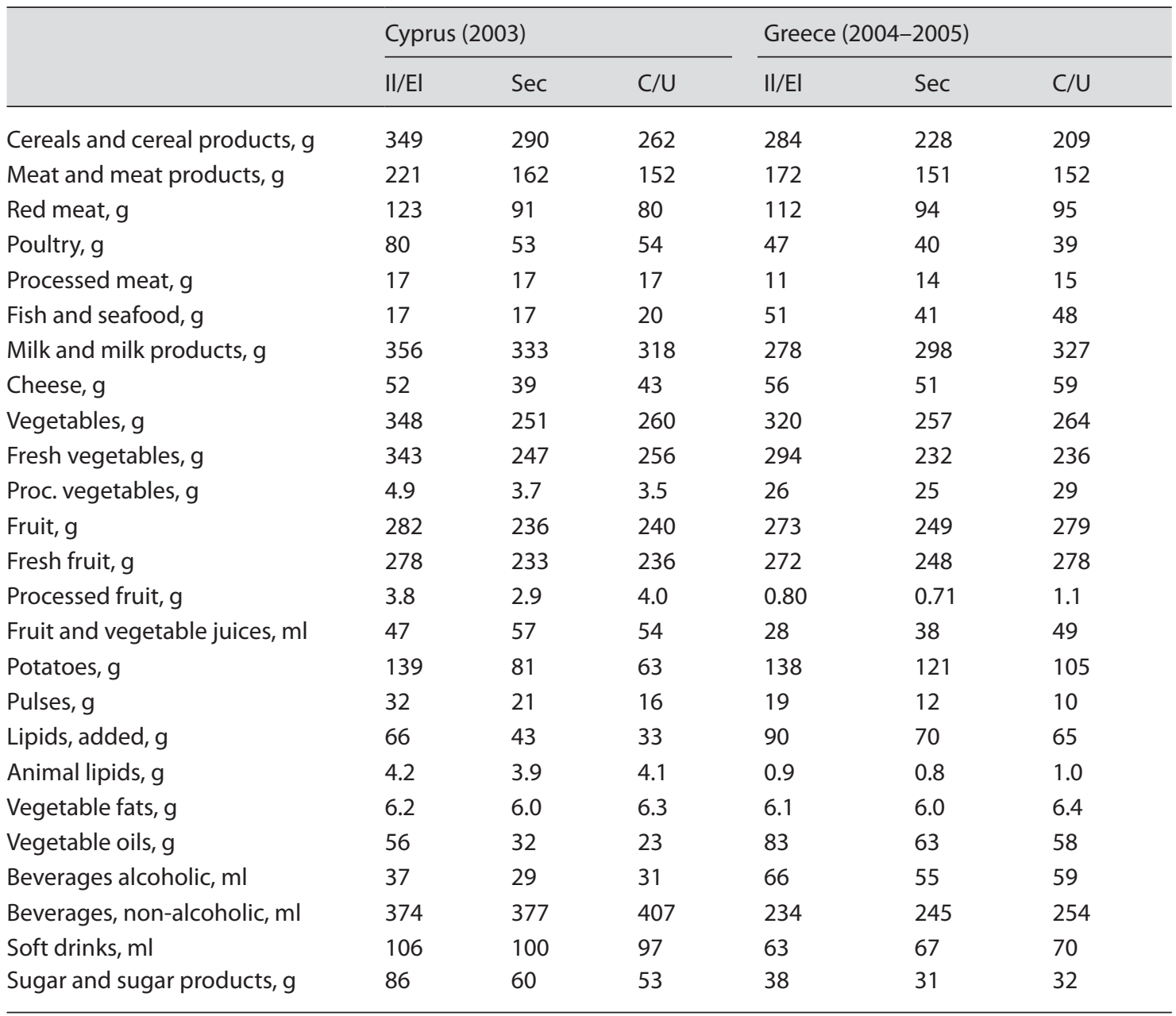

II/EL = Illiterate/Elementary education; $\mathrm{Sec}=$ Secondary education; $\mathrm{C} / \mathrm{U}=$ College/University .

Source: The DAFNE databank (www.nut.uoa.gr).

meat is, however, region-dependent. Red meat is more common in the South (Greece, Cyprus and Portugal) and processed meat is preferred in Central/Eastern European countries, Latvia and Finland. In most cases, the daily availability of poultry is less than half of that of red meat, indicating possible room for recommending the substitution of red with white meat. Exceptions are Hungary and the UK where poultry availability equals that of red meat.

Although out of home consumption of beverages is more common than the inhouse one, the DAFNE data point towards a prevalent acquisition of non-alcoholic 


\begin{tabular}{|c|c|c|c|c|c|c|c|c|}
\hline \multicolumn{3}{|c|}{ Italy (1996) } & \multicolumn{3}{|c|}{ Portugal (2000) } & \multicolumn{3}{|c|}{ Spain (1998-1999) } \\
\hline II/EI & $\mathrm{Sec}$ & $\mathrm{C} / \mathrm{U}$ & II/EI & $\mathrm{Sec}$ & $\mathrm{C} / \mathrm{U}$ & II/EI & $\mathrm{Sec}$ & $\mathrm{C} / \mathrm{U}$ \\
\hline 367 & 320 & 289 & 251 & 201 & 182 & 187 & 157 & 136 \\
\hline 149 & 130 & 118 & 159 & 169 & 155 & 151 & 131 & 113 \\
\hline 77 & 68 & 61 & 89 & 97 & 83 & 60 & 51 & 46 \\
\hline 43 & 35 & 33 & 45 & 41 & 37 & 43 & 34 & 28 \\
\hline 25 & 24 & 20 & 17 & 20 & 17 & 37 & 35 & 30 \\
\hline 38 & 37 & 38 & 81 & 91 & 79 & 63 & 58 & 65 \\
\hline 275 & 269 & 266 & 266 & 313 & 310 & 345 & 331 & 353 \\
\hline 51 & 48 & 51 & 16 & 33 & 26 & 14 & 16 & 17 \\
\hline 191 & 179 & 193 & 137 & 138 & 135 & 125 & 111 & 128 \\
\hline 135 & 123 & 138 & 127 & 126 & 120 & 109 & 92 & 104 \\
\hline 56 & 56 & 55 & 10 & 13 & 15 & 16 & 19 & 24 \\
\hline 242 & 227 & 231 & 193 & 207 & 238 & 206 & 176 & 206 \\
\hline 241 & 226 & 230 & 191 & 205 & 235 & 201 & 171 & 201 \\
\hline 1.2 & 1.5 & 1.3 & 2.2 & 2.6 & 2.9 & 4.6 & 4.9 & 5.2 \\
\hline 6.6 & 11 & 12 & 9.0 & 16 & 17 & 27 & 34 & 32 \\
\hline 85 & 71 & 69 & 188 & 158 & 132 & 102 & 72 & 58 \\
\hline 4.4 & 4.0 & 3.7 & 11 & 5.1 & 3.6 & 12 & 9.0 & 7.1 \\
\hline 71 & 59 & 51 & 53 & 45 & 37 & 50 & 40 & 37 \\
\hline 6.3 & 5.2 & 5.0 & 2.2 & 4.0 & 5.0 & 1.1 & 0.8 & 1.1 \\
\hline 1.6 & 1.5 & 1.2 & 5.1 & 5.7 & 4.4 & 1.5 & 1.7 & 1.9 \\
\hline 64 & 52 & 45 & 46 & 35 & 28 & 48 & 37 & 34 \\
\hline 175 & 136 & 123 & 135 & 90 & 91 & 70 & 77 & 76 \\
\hline 852 & 807 & 811 & 151 & 236 & 243 & 354 & 396 & 422 \\
\hline 39 & 45 & 39 & 60 & 77 & 67 & 83 & 92 & 75 \\
\hline 55 & 46 & 38 & 32 & 23 & 24 & 27 & 25 & 27 \\
\hline
\end{tabular}

beverages (including sugary soft drinks) for household use. With respect to the daily availability of sugar and sugar products in the household, the higher values were recorded in Norway, Austria, Slovenia and Latvia.

Time comparisons, using data presented in the European Nutrition and Health Report 2004 [Elmadfa et al., 2005], were feasible for four countries: Greece (19981999 vs. 2004-2005), Hungary (1991 vs. 2005), Portugal (1995 vs. 2000) and Spain (1990-1991 vs. 1998-1999). In the three Mediterranean countries, household food availability was generally lower in recent years. Exceptions hold for meat, milk and 
Table 5.7. Mean availability of foods and beverages ( $\mathrm{g} \cdot \mathrm{ml} /$ person/day) by country (survey year) and educational attainment in North and Western European countries

\begin{tabular}{|c|c|c|c|c|c|c|}
\hline & \multicolumn{3}{|c|}{ Belgium (1999) } & \multicolumn{3}{|c|}{ Finland (1998) } \\
\hline & II/El. & $\mathrm{Sec}$ & $\mathrm{C} / \mathrm{U}$ & II/El. & $\mathrm{Sec}$ & $\mathrm{C} / \mathrm{U}$ \\
\hline Cereals and cereal products, $\mathrm{g}$ & 272 & 239 & 236 & 223 & 190 & 202 \\
\hline Meat and meat products, $\mathrm{g}$ & 163 & 146 & 135 & 168 & 145 & 133 \\
\hline Red meat, $\mathrm{g}$ & 71 & 55 & 47 & 62 & 49 & 45 \\
\hline Poultry, g & 27 & 24 & 26 & 11 & 12 & 14 \\
\hline Processed meat, $\mathrm{g}$ & 38 & 36 & 32 & 78 & 65 & 57 \\
\hline Fish and seafood, $\mathrm{g}$ & 24 & 23 & 26 & 36 & 26 & 28 \\
\hline Milk and milk products, $\mathrm{g}$ & 232 & 235 & 284 & 564 & 501 & 449 \\
\hline Cheese, $g$ & 48 & 50 & 62 & 44 & 47 & 53 \\
\hline Vegetables, g & 162 & 163 & 175 & 126 & 110 & 134 \\
\hline Fresh vegetables, $\mathrm{g}$ & 122 & 123 & 135 & 106 & 91 & 111 \\
\hline Processed vegetables, $\mathrm{g}$ & 40 & 40 & 40 & 19 & 19 & 23 \\
\hline Fruit, $\mathrm{g}$ & 115 & 115 & 134 & 161 & 145 & 169 \\
\hline Fresh fruit, $\mathrm{g}$ & 110 & 109 & 127 & 151 & 135 & 156 \\
\hline Processed fruit, $\mathrm{g}$ & 5.2 & 5.6 & 6.7 & 10 & 9.4 & 13 \\
\hline Fruit and vegetable juices, $\mathrm{ml}$ & 37 & 46 & 68 & 71 & 82 & 94 \\
\hline Potatoes, $\mathrm{g}$ & 132 & 103 & 81 & 143 & 105 & 81 \\
\hline Pulses, g & n.a. & n.a. & n.a. & 0.87 & 0.68 & 0.86 \\
\hline Lipids, added, g & 36 & 29 & 26 & 39 & 29 & 25 \\
\hline Animal lipids, $\mathrm{g}$ & 11 & 7.1 & 7.0 & 16 & 9.9 & 7.4 \\
\hline Vegetable fats, $\mathrm{g}$ & 17 & 14 & 10 & 19 & 15 & 14 \\
\hline Vegetable oils, g & 8.9 & 8.4 & 8.4 & 3.6 & 3.5 & 3.5 \\
\hline Beverages alcoholic, ml & 127 & 119 & 155 & 86 & 107 & 115 \\
\hline Beverages, non-alcoholic, ml & 463 & 489 & 524 & 588 & 476 & 533 \\
\hline Soft drinks, ml & 163 & 209 & 184 & 74 & 84 & 85 \\
\hline Sugar and sugar products, $\mathrm{g}$ & 56 & 55 & 57 & 65 & 48 & 47 \\
\hline
\end{tabular}

n.a. = Not available; II/EI = Illiterate/Elementary education; $\mathrm{Sec}=$ Secondary education; $\mathrm{C} / \mathrm{U}=\mathrm{College} /$ University Source: The DAFNE databank (www.nut.uoa.gr).

products, vegetables, fruits and beverages (alcoholic and non-alcoholic). In particular, the daily availability of meat and meat products remained stable in Portugal and increased in Greece by $10 \mathrm{~g} /$ person/day, reflecting an increase in processed meat consumption. Vegetable availability increased only in Greece (from 271 to $283 \mathrm{~g} /$ person/day), whereas fruit availability decreased in Greece by $42 \mathrm{~g} /$ person/day and increased in Portugal by $23 \mathrm{~g} /$ person/day. The daily availability of fruit and vegetable juices increased in all countries, triggered probably by the availability of new products in the market. Regarding other beverages, the household daily availability of 


\begin{tabular}{|c|c|c|c|c|c|c|c|c|}
\hline \multicolumn{3}{|c|}{ Ireland (1999) } & \multicolumn{3}{|c|}{ Latvia (2004) } & \multicolumn{3}{|c|}{ Norway (1996/97/98) } \\
\hline II/El. & $\mathrm{Sec}$ & $\mathrm{C} / \mathrm{U}$ & II/EI. & $\mathrm{Sec}$ & $\mathrm{C} / \mathrm{U}$ & II/EI. & $\mathrm{Sec}$ & $\mathrm{C} / \mathrm{U}$ \\
\hline 320 & 275 & 285 & 333 & 258 & 220 & 214 & 198 & 199 \\
\hline 185 & 163 & 151 & 170 & 193 & 174 & 138 & 129 & 114 \\
\hline 49 & 43 & 39 & 57 & 72 & 60 & 61 & 55 & 45 \\
\hline 57 & 58 & 62 & 20 & 26 & 25 & 9.4 & 14 & 15 \\
\hline 61 & 46 & 37 & 82 & 86 & 82 & 46 & 42 & 36 \\
\hline 13 & 13 & 16 & 45 & 37 & 35 & 58 & 50 & 47 \\
\hline 537 & 469 & 443 & 351 & 281 & 280 & 429 & 377 & 387 \\
\hline 13 & 14 & 19 & 35 & 33 & 43 & 39 & 38 & 40 \\
\hline 169 & 137 & 135 & 228 & 214 & 213 & 107 & 104 & 118 \\
\hline 130 & 103 & 105 & 178 & 166 & 165 & 85 & 80 & 91 \\
\hline 39 & 34 & 30 & 49 & 48 & 48 & 22 & 23 & 27 \\
\hline 92 & 96 & 127 & 74 & 115 & 171 & 131 & 129 & 150 \\
\hline 85 & 89 & 118 & 73 & 114 & 167 & 126 & 123 & 143 \\
\hline 7.7 & 6.7 & 9.8 & 1.1 & 1.9 & 3.7 & 5.2 & 5.7 & 7.1 \\
\hline 39 & 57 & 84 & 8.4 & 24 & 44 & 32 & 45 & 63 \\
\hline 238 & 177 & 145 & 359 & 270 & 213 & 178 & 111 & 90 \\
\hline 1.4 & 0.97 & 0.98 & 7.0 & 3.9 & 3.6 & 1.3 & 0.78 & 0.55 \\
\hline 26 & 20 & 20 & 57 & 42 & 33 & 40 & 32 & 27 \\
\hline 13 & 7.7 & 6.7 & 12 & 8.0 & 7.6 & 4.2 & 3.2 & 3.8 \\
\hline 4.5 & 3.7 & 3.7 & 12 & 12 & 6.7 & 35 & 27 & 21 \\
\hline 8.3 & 8.8 & 9.9 & 33 & 24 & 19 & 0.9 & 1.5 & 2.3 \\
\hline 29 & 36 & 61 & 44 & 49 & 60 & 45 & 71 & 92 \\
\hline 686 & 519 & 516 & 366 & 386 & 438 & 896 & 725 & 637 \\
\hline 130 & 123 & 111 & 20 & 26 & 38 & 154 & 193 & 163 \\
\hline 73 & 58 & 52 & 87 & 69 & 65 & 90 & 79 & 76 \\
\hline
\end{tabular}

alcoholic drinks increased in Greece and, interestingly, in Portugal the availability of non-alcoholic beverages in general increased from $129 \mathrm{ml} /$ person/day in 1995 to $171 \mathrm{ml} /$ person/day in 2000 and of soft drinks in particular from $38 \mathrm{ml} /$ person/day in 1995 to $63 \mathrm{ml} /$ person/day in 2000. Data available for Hungary allow comparisons between food availability in the early 1990s and mid-2000s. In most cases, the daily per person availability decreased. Notable increases were, however, noted in the case of vegetables oils (from $15 \mathrm{~g} /$ person/day in 1991 to $27 \mathrm{~g} /$ person/day in 2005) and soft drinks (from $41 \mathrm{ml} /$ person/day in 1991 to $87 \mathrm{ml} /$ person/day in 2005). 
Socio-economic differences in eating practices are often studied in terms of the level of education achieved. Education has been reported to be the strongest and most consistent indicator in assessing socio-economic differences, as it expresses not only the individual's years of schooling, but it might also reflect occupation, income and, even more importantly when it comes to healthy dietary practice, the way an individual perceives current nutritional information [Johansson et al., 1999].

Data presented in tables 5.5-5.7 show that households with heads of higher education generally report lower food acquisitions. Nevertheless, when compared to their lower education counterparts, households of college/university education report higher daily availability of: (a) processed meat in Cyprus and Greece and poultry in Norway, Finland and Latvia; (b) fish and seafood in Central/Eastern Europe and milk, milk products and cheese in particular; (c) fruits but not vegetables in Greece and Portugal; (d) fruits and vegetables in North, West and Central Europe. In Latvia in particular, households of higher education report twice as much daily fruit availability (171 g/person/day), when compared to those of lower education (74 g/person/day). Juices and beverages (alcoholic and non-alcoholic) are purchased more by households of higher education in all countries under study.

\section{Discussion}

From the country members of the DAFNE network, this report presents data for those which are also participants in the ENHR 2009 project. The comparable betweencountries DAFNE data document regional and social disparities in food habits in Europe.

The HBS are not primarily designed to collect nutritional information and the food data bear limitations, which need to be considered when interpreting findings. For example, there are different ways to estimate the per person food availability and methods range from a simple division by the number of household members (as applied in the present analysis) to the application of sophisticated statistical modeling, which have been developed and tested in the DAFNE project [Vasdekis, 2001]. Their application, however, falls beyond the scope of the present report which aims to compare average food choices among different European households. In most cases, no records are collected on the type and quantity of food items and beverages consumed outside the home and not originating from household supplies; food losses and waste, foods given to pets, and meals offered to guests are not consistently collected. Despite their limitations, however, the HBSs provide a resource for the conduct of a wide range of nutritional analyses.

In parallel to enriching the databank, the DAFNE network is also working towards advancing the HBS dietary data. In this context:

(a) The EU supported FAIR-97-3096 project was carried out with the aim to compare individualized HBS data to those collected through INS in four countries, participants 
of the ENHR 2009 project (Belgium, Greece, Norway and the UK) [Trichopoulou and Naska, 2001].

(b) Greek and German DAFNE teams comparatively assessed cost-efficient methods for estimating energy and nutrient availability using HBS data [Naska et al., 2007].

(c) Food supply (FBS) and food availability (HBS) data from 18 DAFNE countries were compared to estimate the extent to which they correlate and were further examined for their ability to predict overall, coronary and cancer mortality through ecological analyses [Naska et al., 2008].

In addition, the FP6-supported HECTOR project (Eating Out: Habits, Determinants, and Recommendations for Consumers and the European Catering Sector) is currently in progress (http://www.nut.uoa.gr/hector/). The project is led by the DAFNE Coordinating Center and, among its objectives, is the exploitation of HBS data on out-of-home food expenditures in order to conceptually assess and monitor the within-home and out-of-home food choices in Europe.

In conclusion, given the potential of the DAFNE data, a system facilitating the regular update of the database, as well as the expansion of the network to embrace all European countries could provide a ready source of data for monitoring public health nutrition in Europe at reasonable cost.

\section{Acknowledgment}

The DAFNE initiative has been supported by the European Commission, in the context of the 'Cooperation in Science and Technology with Central and Eastern European Countries', the 'Agriculture and Agro-Industry, including Fisheries - AIR', the 'Agriculture and Fisheries - FAIR', the 'COST Action 99 - Food Consumption and Composition Data' programs and the Health Monitoring Program of DG-SANCO.

Thanks are due to the Statistical Offices and data providers of all countries presented in this report for supplying the national household budget survey data and supporting documentation, and for their unreserved collaboration.

Statistics Finland was the source of the Finnish HBS. The British HBS data is Crown copyright. It has been made available by the Office for National Statistics (ONS) through the Data Archive, based in the University of Essex. Neither the ONS nor Data Archive bear any responsibility for the analysis or interpretation of the data reported here. 